\title{
The Evaluation of Emergency Logistics Capability in Beijing-Tianjin-Hebei Region Based on Fuzzy Matter-Element Analysis
}

\author{
Xiangguo Ma, Yan Liang, Huihui Yang \\ Logistics Institute, Beijing Wuzi University, Beijing, China \\ Email: mxg105@163.com
}

How to cite this paper: Ma, X.G., Liang, Y. and Yang, H.H. (2017) The Evaluation of Emergency Logistics Capability in Beijing-Tianjin-Hebei Region Based on Fuzzy Matter-Element Analysis. Open Journal of Social Sciences, 5, 52-62.

https://doi.org/10.4236/jss.2017.510005

Received: June 5, 2017

Accepted: October 10, 2017

Published: October 13, 2017

\begin{abstract}
The correct analysis and evaluation on present situation is the key to improving emergency logistics capability in Beijing-Tianjin-Hebei region. This paper took emergency logistics capability in Beijing-Tianjin-Hebei region as the research object. It established analysis model of emergency logistics capability in Beijing-Tianjin-Hebei region based on fuzzy matter-element method. This paper did further study by applying this model. Accordingly, it obtained variation chart of the first-level indicator capability and variation trend chart of comprehensive capability. Finally, this paper summarized and verified research result. The conclusion of this paper has certain instructive effect on improving the emergency logistics capability in Beijing-Tianjin-Hebei region and that could be of referential value for the evaluation and analysis of similar problems.
\end{abstract}

\section{Keywords}

Beijing-Tianjin-Hebei Region, Emergency Logistics, Capability Evaluation, Fuzzy Matter-Element Method

\section{Introduction}

In the process of Beijing-Tianjin-Hebei integration, to improve the capability of emergency prevention and disposal is essential. To evaluate and summarize on present situation correctly as well as reasonably is the beginning of all key points. The fuzzy matter-element method is a method to solve the fuzzy incompatible problems by promoting the association transformation among things, which was applied to the evaluation of problems with multiple factors. In this paper, the problem of regional emergency logistics capability is complex problem with 
many influencing factors. Therefore, fuzzy matter-element method research on emergency logistics capability in Beijing-Tianjin-Hebei region was adopted in this paper.

\section{Research Summary on Regional Logistics Capability}

In the research of regional logistics capability at present, it is mainly based on quantitative analysis abroad, and mainly based on qualitative analysis in domestic. Enterprise logistics capability was measured by Ellinger from five aspects, the time of delivery, stability of service quality, service level, advance notice of out of stock and customer response. Logistics capability in parts of Italy was analyzed and researched by DeMarco through system dynamics model. Regional logistics resources were operated and managed during a short time through the establishment of regional logistics system model to enhance the capability of regional logistics.

In addition, in terms of regional logistics capability evaluation, domestic research mainly includes: 1) The evaluation of regional logistics capability based on principal component. Index system of Sichuan logistics capability evaluation was established by Zhang Jie [1], based on five indicators: the development of logistics economy, production and consumption circulation, human resource, logistics transportation, information level by using principal component analysis. 2) The evaluation of regional logistics capability based on entropy weight method. Firstly, by analyzing the factors of affecting regional logistics capability, then evaluation indicator was selected, next capability evaluation model was established according to entropy weight method to determine the index weight by Qin Jiangui, Xu Dongfang [2]. 3) To evaluation regional logistics capability based on factor analysis. Eighteen cities in Henan province was selected as a sample by Yang Xuemei [3], and then 10 indexes that reflect regional logistics capability were selected, date was obtained by searching statistical yearbook, logistics capability was comprehensively evaluated by applying factor analysis method. 4) The evaluation of regional logistics capability based on fuzzy matter-element method. Firstly, logistics capability elements of Chongqing was studied and summarized, then four regional logistics capability first-class indexes, 11 secondary indexes were selected according to Chongqing logistics industry development situation, fuzzy matter-element analysis model was established, then logistics capability of Chongqing in the future was analyzed and forecasted by making longitudinal contrast [4]. During current study, there is no research on the evaluation of regional emergency logistics capability directly in domestic. But existing research results are significant for regional emergency logistics capability evaluation study. On this basis, Beijing-Tianjin-Hebei region emergency logistics capability was evaluated and studied in this paper.

\section{General Steps of Fuzzy Matter-Element Evaluation}

1) Fuzzy composite element of establishing evaluation object 
Matter-element is the basic unit of matter-element theory, which is consist of evaluation object $M$, characteristic index $C$ and characteristic value $X$. In the evaluation of emergency logistics capability in Beijing-Tianjin-Hebei region, $m$ Evaluation of things and $\mathrm{n}$ main factors $C_{1}, C_{2}, \cdots, C_{n}$ were assumed, each major factor has $\mathrm{p}$ minor factors $C_{11}, C_{12}, \cdots, C_{1 p} ; C_{21}, C_{22}, \cdots, C_{2 p} ; C_{n 1}, C_{n 2}, \cdots, C_{n p}$ the corresponding value is

$$
X_{j i k}(j=1,2, \cdots, m ; i=1,2, \cdots, n ; k=1,2, \cdots, p)
$$

$n$ dimensional fuzzy composite element of $\mathrm{m}$ things $R_{m n}$ is obtained. That is:

$$
R_{m n}=\left[\begin{array}{ccccc} 
& M_{1} & M_{2} & \cdots & M_{m} \\
C_{11} & X_{111} & X_{211} & \cdots & X_{m 11} \\
C_{12} & X_{112} & X_{212} & \cdots & X_{m 12} \\
\cdots & \cdots & \cdots & \cdots & \cdots \\
C_{1 p} & X_{11 p} & X_{21 p} & \cdots & X_{m 1 p} \\
C_{21} & X_{121} & X_{221} & \cdots & X_{m 21} \\
C_{22} & X_{122} & X_{222} & \cdots & X_{m 22} \\
\cdots & \cdots & \cdots & \cdots & \cdots \\
C_{2 p} & X_{12 p} & X_{22 p} & \cdots & X_{m 2 p} \\
\cdots & \cdots & \cdots & \cdots & \cdots \\
C_{n 1} & X_{1 n 1} & X_{2 n 1} & \cdots & X_{m n 1} \\
C_{n 2} & X_{1 n 2} & X_{2 n 1} & \cdots & X_{m n 2} \\
\cdots & \cdots & \cdots & \cdots & \cdots \\
C_{n p} & X_{1 n p} & X_{2 n p} & \cdots & X_{m n p}
\end{array}\right]
$$

2) To determine membership

Because characteristic value $X_{j i}$ of fuzzy matter-element make different contributions to $M_{j}$, and the dimensions are different. So blurring these values $X_{j i}$, which is about to change these values into membership $\mu\left(X_{j i}\right)$. Membership is used to measure the extent of the amount of value attached to a fuzzy set. Generally speaking, it contains two types of memberships, respectively are:

Positive index (the bigger the better):

$$
\mu_{j i}=\frac{X_{j i}-\min X_{j i}}{\max X_{j i}-\min X_{j i}}
$$

Negative index (the smaller the better):

$$
\mu_{j i}=\frac{\max X_{j i}-X_{j i}}{\max X_{j i}-\min X_{j i}}
$$

Among them, $\max X_{j i}$ and $\min X_{j i}$ respectively represent the maximum and minimum of all magnitudes $X_{j i}(j=1,2, \cdots, m ; i=1,2, \cdots, n)$ corresponding to the $i$ th index of each evaluation object. Therefore, magnitudes $X_{j i}$ of fuzzy composite element $R_{m n}$ (1) is transformed into membership $\mu_{j i}$, fuzzy composite element $R_{m n}^{\prime}$ composed of optimal membership degree is established according to Equation (2) and Equation (3), it is given by: 


$$
R_{m n}^{\prime}=\left[\begin{array}{ccccc} 
& M_{1} & M_{2} & \cdots & M_{m} \\
C_{11} & \mu_{111} & \mu_{211} & \cdots & \mu_{m 11} \\
C_{12} & \mu_{112} & \mu_{212} & \cdots & \mu_{m 12} \\
\cdots & \cdots & \cdots & \cdots & \cdots \\
C_{1 p} & \mu_{11 p} & \mu_{21 p} & \cdots & \mu_{m 1 p} \\
C_{21} & \mu_{121} & \mu_{221} & \cdots & \mu_{m 21} \\
C_{22} & \mu_{122} & \mu_{222} & \cdots & \mu_{m 22} \\
\cdots & \cdots & \cdots & \cdots & \cdots \\
C_{2 p} & \mu_{12 p} & \mu_{22 p} & \cdots & \mu_{m 2 p} \\
\cdots & \cdots & \cdots & \cdots & \cdots \\
C_{n 1} & \mu_{1 n 1} & \mu_{2 n 1} & \cdots & \mu_{m n 1} \\
C_{n 2} & \mu_{1 n 2} & \mu_{2 n 1} & \cdots & \mu_{m n 2} \\
\cdots & \cdots & \cdots & \cdots & \cdots \\
C_{n p} & \mu_{1 n p} & \mu_{2 n p} & \cdots & \mu_{m n p}
\end{array}\right]
$$

3) To construct evaluation index weight compound element

a) $C_{n p}$ and $\omega_{n p}$

$$
\begin{gathered}
C_{n p} \frac{1}{m}\left(\mu_{1 n p}+\mu_{2 n p}+\cdots+\mu_{m n p}\right)=\frac{1}{m} \sum_{j=1}^{m} \mu_{j n p} \\
\omega_{n p}=\frac{1}{m} \sum_{j=1}^{m} \mu_{j n p} / \frac{1}{m} \sum_{j=1}^{m} \sum_{i=1}^{n} \sum_{k=1}^{p} \mu_{m i k}
\end{gathered}
$$

b) Weight

To establish a minor factor of weighted composite element $R_{\text {wik }}$, that is:

$$
R_{\text {øik }}=\left[\begin{array}{ccccccccccccc}
C_{11} & C_{12} & \cdots & C_{1 p} & C_{21} & C_{22} & \cdots & C_{2 p} & \cdots & C_{n 1} & C_{n 2} & \cdots & C_{n p} \\
\omega_{11} & \omega_{12} & \cdots & \omega_{1 p} & \omega_{21} & \omega_{22} & \cdots & \omega_{2 p} & \cdots & \omega_{n 1} & \omega_{n 2} & \cdots & \omega_{n p}
\end{array}\right]
$$

Supposing $R_{\omega i}$ represents main factor weighted composite element, we use method to subjectively determine the weight of indexes, the weighted composite element of main factor is established, that is:

$$
R_{\omega i}=\left[\begin{array}{cccc}
C_{1} & C_{2} & \cdots & C_{n} \\
\omega_{1} & \omega_{2} & \cdots & \omega_{n}
\end{array}\right]
$$

4) To define central composite fuzzy matter-element

Supposing $R_{k}$ represents central composite fuzzy matter-element,

$$
R_{k}=R_{m n}^{\prime} * R_{\text {மik }}
$$

where " " indicates that multiplication is first, then do addition, according to Equation (4) and Equation (7), $R_{k}$ is obtained, that is:

$$
R_{k}=\left[\begin{array}{ccccc} 
& M_{1} & M_{2} & \cdots & M_{m} \\
C_{1} & K_{11}=\sum_{k=1}^{p} \mu_{11 k} \omega_{1 k} & K_{21}=\sum_{k=1}^{p} \mu_{21 k} \omega_{1 k} & \cdots & K_{m 1}=\sum_{k=1}^{p} \mu_{m 1 k} \omega_{1 k} \\
C_{2} & K_{12}=\sum_{k=1}^{p} \mu_{12 k} \omega_{2 k} & K_{22}=\sum_{k=1}^{p} \mu_{22 k} \omega_{2 k} & \cdots & K_{m 2}=\sum_{k=1}^{p} \mu_{m 2 k} \omega_{2 k} \\
\cdots & \cdots & \cdots & \cdots & \cdots \\
C_{n} & K_{1 n}=\sum_{k=1}^{p} \mu_{1 n k} \omega_{n k} & K_{2 n}=\sum_{k=1}^{p} \mu_{2 n k} \omega_{n k} & \cdots & K_{m n}=\sum_{k=1}^{p} \mu_{m n k} \omega_{n k}
\end{array}\right] \text { (9) }
$$


5) To establish comprehensive evaluation of compound fuzzy matter-element

Supposing comprehensive evaluation of compound fuzzy matter-element is $R_{D}$, before which single evaluation compound fuzzy matter-element $R_{d}$ is obtained by the equation $R_{d}=R_{k} * R_{\omega i}$, Equation (8) and Equation (9), $R_{d}$ is given by:

$$
R_{d}=\left[\begin{array}{ccccc} 
& M_{1} & M_{2} & \cdots & M_{m} \\
C_{1} & d_{11}=K_{11} \omega_{1} & d_{21}=K_{21} \omega_{1} & \cdots & d_{m 1}=K_{m 1} \omega_{1} \\
C_{2} & d_{12}=K_{12} \omega_{2} & d_{22}=K_{22} \omega_{2} & \cdots & d_{m 2}=K_{m 2} \omega_{2} \\
\cdots & \cdots & \cdots & \cdots & \cdots \\
C_{n} & d_{1 n}=K_{1 n} \omega_{n} & d_{2 n}=K_{2 n} \omega_{n} & \cdots & d_{m n}=K_{m n} \omega_{n}
\end{array}\right]
$$

Finally, on the basis of the above equation, comprehensive evaluation of compound fuzzy matter-element $R_{D}$ is:

$$
R_{D}=\left[\begin{array}{cccc}
M_{1} & M_{2} & \cdots & M_{m} \\
D_{1} & D_{2} & \cdots & D_{m}
\end{array}\right]
$$

Among which, the equation $D_{j}=\sum d_{j i}(j=1,2, \cdots, m ; i=1,2, \cdots, n)$ is the final comprehensive evaluation value of the th thing to be obtained.

\section{To Establish Beijing-Tianjin-Hebei Region Emergency Logistics Capability Evaluation Index}

According to the status of Beijing-Tianjin-Hebei region emergency logistics, we can establish two-level rating system. Specific indicators are emergency logistics human resources support capability (including the proportion of people who receive higher education $C_{11}(\%)$; the scale of employment in information and information technology industry $C_{12}$ (ten thousand persons); employment in transportation industry $C_{13}$ (ten thousand persons); the scale of rescue team $C_{14}$ (person); emergency logistics economic support capability (including the GDP of Beijing-Tianjin-Hebei $C_{21}$ (one hundred million yuan)); fixed assets investment in transportation industry $C_{22}$ (one hundred million yuan); fixed assets investment in information and information technology industry $C_{23}$ (one hundred million yuan); disaster relief material reserve expenditure $C_{24}$ (ten thousand yuan); emergency logistics information system security capability (including the internet penetration rate $C_{31}(\%)$ ); the perfection degree of emergency database $C_{32}(\%)$; the perfection degree of regional emergency $C_{33}$ (\%); infrastructure equipment support capability (including highway mileage $C_{41}$ (ten thousand kilometers)); railway mileage $C_{42}$ (ten thousand kilometers); cargo handling capacity of ports $C_{43}$. (ten million tons); vehicles of freight transportation $C_{44}$. (ten thousand tractor); the satisfaction of emergency material coverage $C_{45}(\%)$; the reliability of emergency access $C_{46}$; the number of beds in medical and health institutions $C_{47}$. (ten thousand sheet) and emergency logistics management capability(including the capability of pre-arranged planning of emergency $C_{51}$; the capability of government coordination $C_{52}$; the capability of law guarantee $C_{53}$; the capability of expert decision decisionmaking $C_{54}$; the cooperation degree of regional logistics $C_{55}$. 


\section{Beijing-Tianjin-Hebei Region Emergency Logistics Capability Fuzzy Matter-Element Comprehensive Evaluation}

\subsection{To Construct the Matter-Element Analysis Model of Beijing-Tianjin-Hebei Region Emergency Logistics Capability}

1) To establish fuzzy composite element of Beijing-Tianjin-Hebei region emergency logistics capability

In this paper, these six years from 2009-2004 is regarded as six things to be evaluated, these 23 indexes that are selected from preceding text, the related index data is regarded as characteristic value. The quantitative index was obtained by querying China statistical yearbook, the National Bureau of statistics and relevant government websites, Beijing, Tianjin, Hebei three relevant index, qualitative index was set by using expert scoring, divided into nine grades \{very good, fine, better, good, general, poor, poorer, very poor, extreme poor, $(9,8,7,6,5,4$, $3,2,1)\}$ corresponding to [1] [9], finally all the evaluation index data of BeijingTianjin-Hebei region is shown in Table 1.

Table 1. Quantitative value of each index data.

\begin{tabular}{|c|c|c|c|c|c|c|}
\hline & 2009 & 2010 & 2011 & 2012 & 2013 & 2014 \\
\hline $\mathrm{C}_{11}$ & 11.4 & 12.3 & 13.0 & 14.3 & 16.5 & 17.8 \\
\hline $\mathrm{C}_{12}$ & 44.74 & 50.2 & 57.03 & 62.4 & 70.44 & 73.52 \\
\hline $\mathrm{C}_{13}$ & 87.84 & 86.67 & 93.22 & 96.21 & 101.17 & 109.49 \\
\hline $\mathrm{C}_{14}$ & 200,936 & 243,312 & 390,763 & 671,529 & 795,501 & 898,195 \\
\hline $\mathrm{C}_{21}$ & $36,910.36$ & $43,732.3$ & $52,074.97$ & $57,348.29$ & $62,685.77$ & $66,474.45$ \\
\hline $\mathrm{C}_{22}$ & 2020.93 & 2552.2 & 2403.75 & 2947.81 & 3364.83 & 3539.43 \\
\hline $\mathrm{C}_{23}$ & 201.75 & 230.9 & 261.86 & 326.03 & 377.82 & 400.96 \\
\hline $\mathrm{C}_{24}$ & 472.3 & 1059.8 & 1303.1 & 1526.4 & 1593.7 & 1732.3 \\
\hline $\mathrm{C}_{31}$ & 35.6 & 40.5 & 44.9 & 49.5 & 54.0 & 55.8 \\
\hline $\mathrm{C}_{32}$ & 50.1 & 55.7 & 64.1 & 74.9 & 83.6 & 91.2 \\
\hline $\mathrm{C}_{33}$ & 3.1 & 3.9 & 5.1 & 5.6 & 5.9 & 6.7 \\
\hline $\mathrm{C}_{41}$ & 18.72 & 19.02 & 19.35 & 19.99 & 21.19 & 21.72 \\
\hline $\mathrm{C}_{42}$ & 0.69 & 0.69 & 0.73 & 0.78 & 0.86 & 0.89 \\
\hline $\mathrm{C}_{43}$ & 8.90 & 10.21 & 11.64 & 12.38 & 13.90 & 14.94 \\
\hline $\mathrm{C}_{44}$ & 84.36 & 97.98 & 114.78 & 127.81 & 166.09 & 174.46 \\
\hline $\mathrm{C}_{45}$ & 53.6 & 58 & 65.9 & 67.7 & 74 & 86.3 \\
\hline $\mathrm{C}_{46}$ & 3.6 & 4.4 & 5.3 & 6.1 & 6.9 & 7.6 \\
\hline $\mathrm{C}_{47}$ & 36.91 & 39.13 & 41.06 & 43.81 & 46.52 & 49.36 \\
\hline $\mathrm{C}_{51}$ & 4.9 & 5.7 & 6.3 & 6.7 & 7.2 & 8.1 \\
\hline $\mathrm{C}_{52}$ & 4.3 & 5.1 & 6.1 & 6.6 & 7 & 7.7 \\
\hline $\mathrm{C}_{53}$ & 4.6 & 5.3 & 5.7 & 6 & 6.6 & 7.1 \\
\hline $\mathrm{C}_{54}$ & 5.4 & 5.7 & 6.4 & 6.9 & 7.6 & 8.3 \\
\hline $\mathrm{C}_{55}$ & 2.6 & 3.4 & 3.9 & 4.4 & 5.6 & 6.9 \\
\hline
\end{tabular}


According to the data in Table 1, membership grade compound fuzzy matterelement is obtained by using membership principle, membership compound fuzzy matter-element $R_{m n}^{\prime}$ is obtained as shown in Equation (12):

$$
R_{m n}^{\prime}=\left[\begin{array}{ccccccc} 
& 2009 & 2010 & 2011 & 2012 & 2013 & 2014 \\
C_{11} & 0 & 0.14 & 0.25 & 0.45 & 0.79 & 1 \\
C_{12} & 0 & 0.19 & 0.43 & 0.61 & 0.89 & 1 \\
C_{13} & 0.05 & 0 & 0.29 & 0.42 & 0.64 & 1 \\
C_{14} & 0 & 0.06 & 0.27 & 0.67 & 0.85 & 1 \\
C_{21} & 0 & 0.23 & 0.51 & 0.69 & 0.87 & 1 \\
C_{22} & 0 & 0.35 & 0.25 & 0.61 & 0.89 & 1 \\
C_{23} & 0 & 0.15 & 0.30 & 0.62 & 0.88 & 1 \\
C_{24} & 0 & 0.47 & 0.66 & 0.84 & 0.89 & 1 \\
C_{31} & 0 & 0.24 & 0.46 & 0.69 & 0.91 & 1 \\
C_{32} & 0 & 0.14 & 0.34 & 0.60 & 0.82 & 1 \\
C_{33} & 0 & 0.22 & 0.56 & 0.69 & 0.48 & 1 \\
C_{41} & 0 & 0.10 & 0.21 & 0.42 & 0.82 & 1 \\
C_{42} & 0 & 0 & 0.20 & 0.45 & 0.85 & 1 \\
C_{43} & 0 & 0.22 & 0.45 & 0.58 & 0.83 & 1 \\
C_{44} & 0 & 0.15 & 0.34 & 0.48 & 0.91 & 1 \\
C_{45} & 0 & 0.13 & 0.38 & 0.43 & 0.62 & 1 \\
C_{46} & 0 & 0.20 & 0.43 & 0.63 & 0.83 & 1 \\
C_{47} & 0 & 0.18 & 0.33 & 0.55 & 0.77 & 1 \\
C_{51} & 0 & 0.25 & 0.44 & 0.56 & 0.72 & 1 \\
C_{52} & 0 & 0.24 & 0.55 & 0.68 & 0.79 & 1 \\
C_{53} & 0 & 0.28 & 0.44 & 0.56 & 0.80 & 1 \\
C_{54} & 0 & 0.10 & 0.34 & 0.52 & 0.76 & 1 \\
C_{55} & 0 & 0.19 & 0.30 & 0.42 & 0.70 & 1
\end{array}\right]
$$

Then, weighted composite element $R_{\omega i k}$ is established, as shown in Equation (13).

$$
\begin{aligned}
& C_{11} 0.0387 \quad C_{12} 0.0461 \quad C_{13} 0.0353 \quad C_{14} 0.0422 \\
& C_{21} 0.0488 \quad C_{22} 0.0457 \quad C_{23} 0.0436 \quad C_{24} 0.0569 \\
& R_{\text {कik }}=C_{31} 0.0486 \quad C_{32} 0.0427 \quad C_{33} 0.0480 \\
& C_{41} 0.0377 \quad C_{42} 0.0369 \quad C_{43} 0.0454 \quad C_{44} 0.0425 \quad C_{45} 0.0379 \quad C_{46} 0.0454 \quad C_{47} 0.0419 \\
& C_{51} 0.0438 \quad C_{52} 0.0477 \quad C_{53} 0.0455 \quad C_{54} 0.0402 \quad C_{55} 0.0384
\end{aligned}
$$

2) To establish Beijing-Tianjin-Hebei region emergency logistics capability central composite fuzzy matter-element

Supposing $R_{k}$ represents Beijing-Tianjin-Hebei region emergency logistics capability centralized composite fuzzy matter-element, Equation (19) is given by equation $R_{k}=R_{m n}^{\prime} * R_{\omega i k}$, Equation (12) and Equation (13).

$$
R_{k}=\left[\begin{array}{ccccccc} 
& 2009 & 2010 & 2011 & 2012 & 2013 & 2014 \\
C_{1} & 0.0018 & 0.0166 & 0.0509 & 0.0899 & 0.1304 & 0.1624 \\
C_{2} & 0 & 0.0601 & 0.0872 & 0.1364 & 0.1722 & 0.1950 \\
C_{3} & 0 & 0.0283 & 0.0636 & 0.0925 & 0.1163 & 0.1393 \\
C_{4} & 0 & 0.0417 & 0.0977 & 0.1471 & 0.2320 & 0.2876 \\
C_{5} & 0 & 0.0462 & 0.0899 & 0.1193 & 0.1631 & 0.2157
\end{array}\right]
$$


3) To define Beijing-Tianjin-Hebei region emergency logistics capability central composite fuzzy matter-element

By expert scoring, we get four first-level evaluation indexes, their weighted composite element $R_{\omega i}$ is shown in Equation (15).

$$
R_{\omega i}=\left[\begin{array}{ccccc}
C_{1} & C_{2} & C_{3} & C_{4} & C_{5} \\
0.0752 & 0.4734 & 0.1503 & 0.0551 & 0.2460
\end{array}\right]
$$

$R_{D}$ represents comprehensive evaluation compound fuzzy matter-element. Firstly, $R_{d}$ is obtained by equation $R_{d}=R_{k} * R_{\omega i}$, adopting Equation (14) and Equation (15), as shown in Equation (16).

$$
R_{d}=\left[\begin{array}{ccccccc} 
& 2009 & 2010 & 2011 & 2012 & 2013 & 2014 \\
C_{1} & 0.0001 & 0.0012 & 0.0038 & 0.0067 & 0.0098 & 0.0122 \\
C_{2} & 0 & 0.0285 & 0.0413 & 0.0646 & 0.0815 & 0.0923 \\
C_{3} & 0 & 0.0042 & 0.0096 & 0.0139 & 0.0175 & 0.0209 \\
C_{4} & 0 & 0.0023 & 0.0054 & 0.0081 & 0.0128 & 0.0158 \\
C_{5} & 0 & 0.0114 & 0.0221 & 0.0293 & 0.0401 & 0.0531
\end{array}\right]
$$

Finally, comprehensive evaluation compound fuzzy matter-element $R_{D}$ is given by:

$$
R_{D}=\left[\begin{array}{ccccccc} 
& 2009 & 2010 & 2011 & 2012 & 2013 & 2014 \\
D_{j} & 0.001 & 0.0476 & 0.0822 & 0.1226 & 0.1617 & 0.1944
\end{array}\right]
$$

We could find $D_{6}>D_{5}>D_{4}>D_{3}>D_{2}>D_{1}$, there is increasing trends of Beijing-Tianjin-Hebei region emergency logistics capability from the year 2009 to the year 2014 .

\subsection{Result Analysis}

1) Comprehensive capability evaluation of Beijing-Tianjin-Hebei region emergency logistics

In order to facilitate evaluation and analysis, Equation (17) is transformed into figure, as shown in Figure 1 and Figure 2.

We can see intuitively from Figure 1 and Figure 2 that Beijing-Tianjin-Hebei region emergency logistics capability maintains growth from the year 2009 to

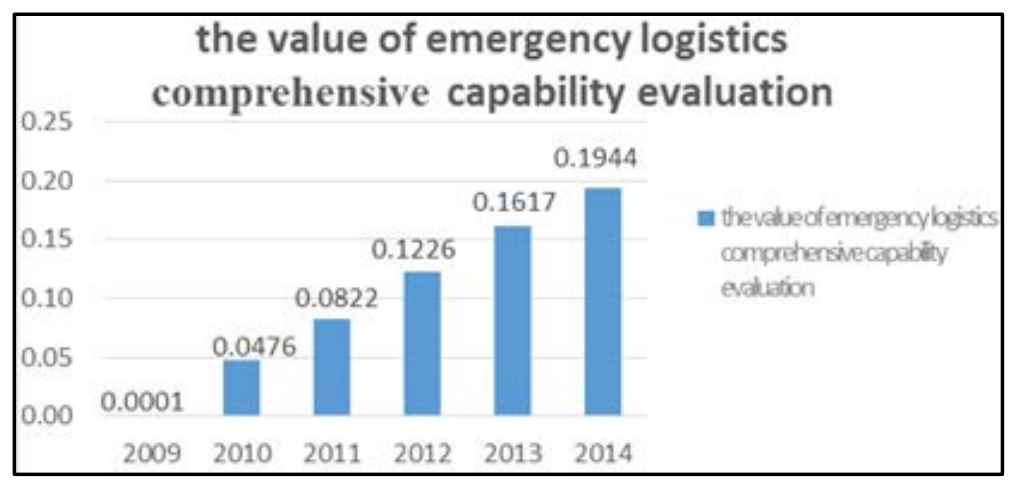

Figure 1. The histogram of Beijing-Tianjin-Hebei region emergency logistics capability comprehensive evaluation results. 


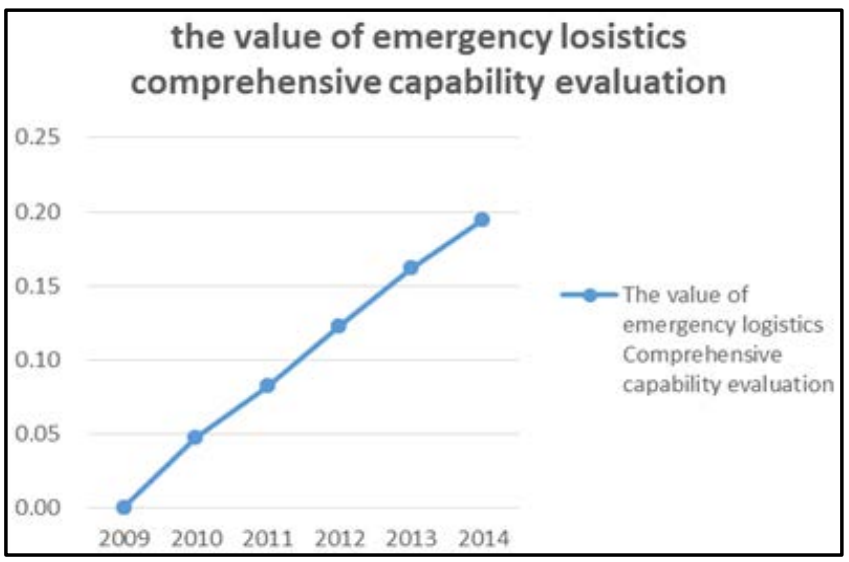

Figure 2. The curves chart of Beijing-Tianjin-Hebei region emergency logistics capability comprehensive evaluation results.

the year 2014, but the growth rate slowed down year by year. From the year 2009 to the year 2010, Beijing-Tianjin-Hebei region emergency logistics capability rose sharply.

2) The evaluation of Beijing-Tianjin-Hebei region emergency logistics capability of indexes at all levels.

Beijing-Tianjin-Hebei region emergency logistics capability is the result of comprehensive function of each first-class influence index, so we need to make further analysis. Equation (16) is transformed into Figure 3, shown as following.

Figure 3 reveals that each first-class index of Beijing-Tianjin-Hebei region emergency logistics capability took on an increasing tendency, the support capability of economic growth was most obvious, followed by which was emergency logistics management capability and information system security capability, human resources support capability and infrastructure support capability showed a smaller increase. From Equation (15), in all of first-class indexes, the support capability of economic growth in emergency logistics capability accounted for the maximum weight, followed by emergency logistics management capability and information systems security capability, the weight of human resources support capability and infrastructure support capability was smallest. Combined with these two aspects, we could find that the first-class index elements of economic support made the biggest impact on Beijing- Tianjin-Hebei region emergency logistics capability. But from Figure 1, we could find that disaster relief materials reserve expenditure $C_{24}$ accounted for the highest weight, followed by Beijing-Tianjin-Hebei regional GDP index $C_{21}$, but the growth rate of these two indexes was relatively low in the past two years, which showed that it needs to ensure the rapid development of regional economy and continuing to increase the reserves of disaster relief supplies to improve regional emergency logistics capability.

The weigh of the first-class index of emergency logistics management capability is only second to the economic support capability, but we can see from Table 2, the cooperation degree of regional emergency logistics in it's secondary 


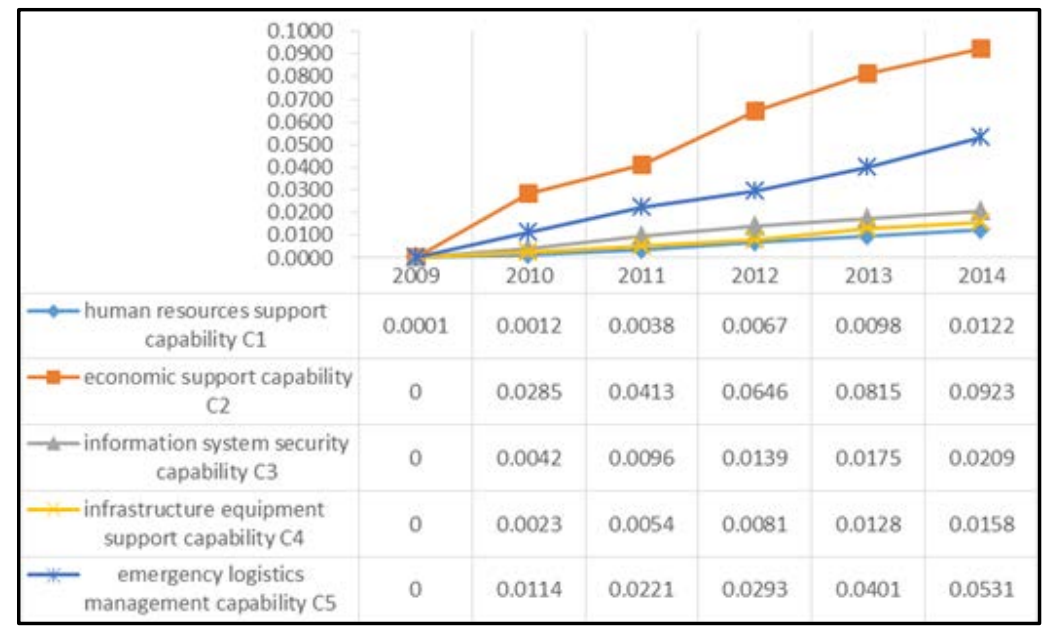

Figure 3. The curves chart of Beijing-Tianjin-Hebei region emergency logistics capability comprehensive evaluation results.

Table 2. Each index weight.

\begin{tabular}{|c|c|c|c|c|c|c|c|c|}
\hline & 2009 & 2010 & 2011 & 2012 & 2013 & 2014 & $\overline{\mu_{i k}}$ & $\omega_{i k}$ \\
\hline $\mathrm{C} 11$ & 0 & 0.14 & 0.25 & 0.45 & 0.79 & 1 & 0.438 & 0.0387 \\
\hline C12 & 0 & 0.19 & 0.43 & 0.61 & 0.89 & 1 & 0.521 & 0.0461 \\
\hline $\mathrm{C} 13$ & 0.05 & 0 & 0.29 & 0.42 & 0.64 & 1 & 0.399 & 0.0353 \\
\hline C14 & 0 & 0.06 & 0.27 & 0.67 & 0.85 & 1 & 0.477 & 0.0422 \\
\hline $\mathrm{C} 21$ & 0 & 0.23 & 0.51 & 0.69 & 0.87 & 1 & 0.551 & 0.0488 \\
\hline $\mathrm{C} 22$ & 0 & 0.35 & 0.25 & 0.61 & 0.89 & 1 & 0.516 & 0.0457 \\
\hline $\mathrm{C} 23$ & 0 & 0.15 & 0.30 & 0.62 & 0.88 & 1 & 0.493 & 0.0436 \\
\hline $\mathrm{C} 24$ & 0 & 0.47 & 0.66 & 0.84 & 0.89 & 1 & 0.642 & 0.0569 \\
\hline C31 & 0 & 0.24 & 0.46 & 0.69 & 0.91 & 1 & 0.549 & 0.0486 \\
\hline C32 & 0 & 0.14 & 0.34 & 0.60 & 0.82 & 1 & 0.483 & 0.0427 \\
\hline C33 & 0 & 0.22 & 0.56 & 0.69 & 0.78 & 1 & 0.542 & 0.0480 \\
\hline C41 & 0 & 0.1 & 0.21 & 0.42 & 0.82 & 1 & 0.426 & 0.0377 \\
\hline C42 & 0 & 0 & 0.2 & 0.45 & 0.85 & 1 & 0.417 & 0.0369 \\
\hline $\mathrm{C} 43$ & 0 & 0.22 & 0.45 & 0.58 & 0.83 & 1 & 0.513 & 0.0454 \\
\hline C44 & 0 & 0.15 & 0.34 & 0.48 & 0.91 & 1 & 0.480 & 0.0425 \\
\hline $\mathrm{C} 45$ & 0 & 0.13 & 0.38 & 0.43 & 0.62 & 1 & 0.428 & 0.0379 \\
\hline C46 & 0 & 0.20 & 0.43 & 0.63 & 0.83 & 1 & 0.513 & 0.0454 \\
\hline C47 & 0 & 0.18 & 0.33 & 0.55 & 0.77 & 1 & 0.473 & 0.0419 \\
\hline C51 & 0 & 0.25 & 0.44 & 0.56 & 0.72 & 1 & 0.495 & 0.0438 \\
\hline C52 & 0 & 0.24 & 0.53 & 0.68 & 0.79 & 1 & 0.539 & 0.0477 \\
\hline C53 & 0 & 0.28 & 0.44 & 0.56 & 0.80 & 1 & 0.513 & 0.0455 \\
\hline C54 & 0 & 0.10 & 0.34 & 0.52 & 0.76 & 1 & 0.454 & 0.0402 \\
\hline C55 & 0 & 0.19 & 0.30 & 0.42 & 0.70 & 1 & 0.434 & 0.0384 \\
\hline
\end{tabular}


measurable index still need to be strengthened. In addition, the weight of Internet penetration rate $C_{31}$, the degree of regional emergency information sharing $C_{33}$, and government coordination capability $C_{52}$ are higher, so emergency logistics capability can be improved by enhancing these capabilities.

\section{Conclusions}

The following conclusions are drawn by the analysis and evaluation on BeijingTianjin-Hebei region emergency logistics capability:

1) Fuzzy matter-element method is suitable for solving the quantitative and qualitative analysis, the calculation process is simple and clear, which can clearly reflect the impact of each index on regional emergency logistics capability.

2) Disaster relief materials reserve expenditure and Gross Regional Product are the main factors that influence on Beijing-Tianjin-Hebei region emergency logistics capability, regional emergency logistics level can be improved by increasing the reserves of relief supplies and improving the regional economic strength.

\section{Acknowledgements}

This work was supported by Beijing Social Science Fund Project (15JGB071) and Beijing Wuzi University high level scientific research project Foster fund projects (GJB20143006) and funding project for Youth Talent Cultivation Plan of Beijing City University Under the grant number (CIT \& TCD201504051).

\section{References}

[1] Zhang, J. (2013) Research on the Evaluation of Regional Logistics Capability in Sichuan Province Based on Principal Component Analysis. Foreign Capital in China, $10,264$.

[2] Qin, J.G., Xu, D.F., Chen, Y. and Xie, M. (2010) Research on the Evaluation of Regional Logistics Capability of Regional Logistics Capability of Three Cities in South of Jiangsu Based on Entropy Weight Method. Value Engineering ,19, 36-37.

[3] Yang, X.M. (2011) Research on Regional Logistics Capability Evaluation of Henan Province Based on Factor Analysis. Modern Business, 9, 27-31.

[4] Wang, Y.L. and Zhou, T. (2010) Evaluation of Regional Logistics Development Level Based on Fuzzy Matter-Element. Journal of Beijing Jiaotong University, 07, 37. 